\title{
SUNLIGHT SUPPLY AND GAS EXCHANGE SYSTEMS IN MICROALGAL BIOREACTOR
}

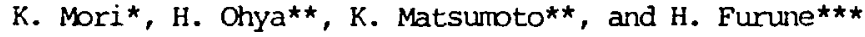 \\ *Keio University, 3-14-1 Hiyoshi, Kohoku-ku, Yokohana 223, Japan; **Yokohama \\ National University, Tokiwadai, Hodogaya-ku, Yokohama 240, Japan; *k*La \\ Foret Engineering and Information Service Co., 2-7-8 Toranomon, Minato-ku, \\ Tokyo 105, Japan
}

\section{ABSTRACT}

The bioreactor with sunlight supply system and gas exchange systems presented here has proved feasible in ground tests and shows much promise for space use as a CELSS device. Our chief conclusions concerning the specification of total system needed for a life support system for a man in a space station are the following.

(1) Sunlight supply system : compactness and low electrical consumption.

(2) Bioreactor system : high density and growth rate of chlorella.

(3) Gas exchange system : enough for $\mathrm{O}_{2}$ production and $\mathrm{CO}_{2}$ assinilation.

\section{INTRODUCTION}

The sunlight supply system /1-2/ presented will provide the visible solar radiation necessary for the various activities in the space station, such as cultivation experiments on algae, plants, fishes, birds, and animals room, lighting for modules, and crew sun-bathing. Even natural solar rays reaching the earth's surface contain ultraviolet rays of medium and long wavelengths (UV-B and UV-A) and infrared and heat rays, all of which are harmful to life. On a space station, the most dangerous short-wavelength ultraviolet rays (UB-C), $x-$ rays, and gamma-rays are added, and those cited above are present in markedly higher intensity. It will thus only be after elimination of these harmful rays that spacial solar rays will be utilizable in the space station for activities related to the life sciences. With respect to the Regenerative Life Support System in CFISS, the main function of the microalgal bioreactor with gas exchange system to supply $\mathrm{O}_{2}$ and assimulate exhaust of $\mathrm{CO}_{2}$ for a man in a space station, though another would be to produce algal biomass for a human food and medicine: the biomass protein, carbohydrate, and $f$-carotene would be useful.

CONCEPT AND BASIC DESIGN OF TOTAL SYSTEM

\section{Sunlight Supply System}

The basic design of the sunlight supply system is shown in Figure $1 / 1 \%$ The solar rays are collected and concentrated by a factor of 10,000 by means of a solar collector assembly composed of many small Fresnel lenses.

Limitation of the admitted spectral band to the visible region (380-770 $\mathrm{nm}$ wavelength) is made possible by the chromatic abberation of the individual Fresnel lenses. Chromatic aberration caused by the Fresnel lenses separates the focal points of different wavelengths, so that placing the end of the fiber optic cable at the focus of green light admits mainly the visible spectrum (Figure 2). The solar rays focused by each small lens are fed through the well-polished terminal end of a flexible light-conducting fiber, and are confined within its quartz core for transmission to the required location.

Solar oollection is performed by Fresnel lenses assembled in a honeycomb lattice as illustrated in Figure 1. The front face of each is covered by a protector serving also as a filter. The protector is made of quartz, is resistant to scratching, and is sufficiently thick to withstand most inpinging meteoroids, debris and deposits that may be encountered. Moreover, in the event of damage to the protector, the affected unit can be cut off and sealed off from the rest of the system, which can continue functioning ing independently. The space between protector and array

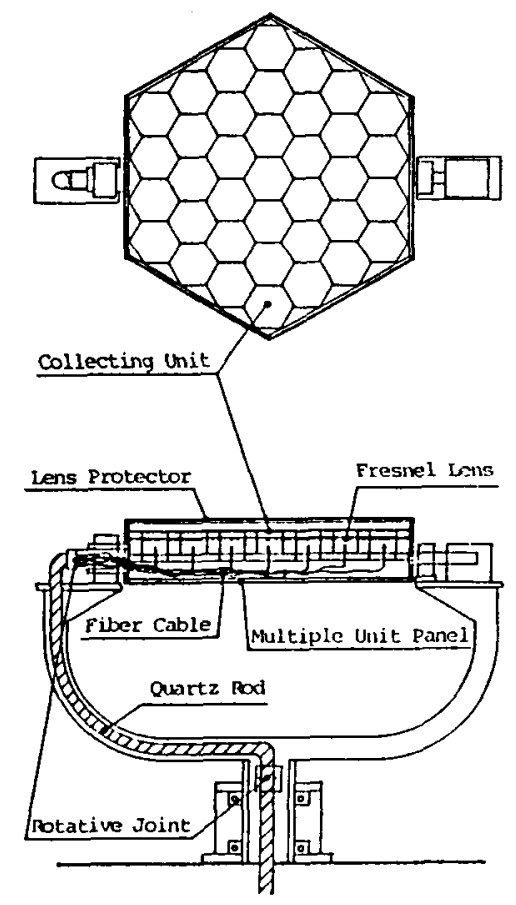

Fig. I Basic design of solar collector. 
independently. The space between protector and array is filled with an inert gas to allow temperature control and to suppress evaporation of the component materials.

Figure 3 is a graph showing the HIMAWARI light collector's visible spectrum transmissivity. As can be seen in Figure 3, almost all ultraviolet radiation is excluded, while infrared heat radiation is cut by about forty percent. Light spectrum power analysis was carried out with a Princeton Applied Research Model 1450 OMA with an $0.5 \mathrm{~nm}$ wavelength increment

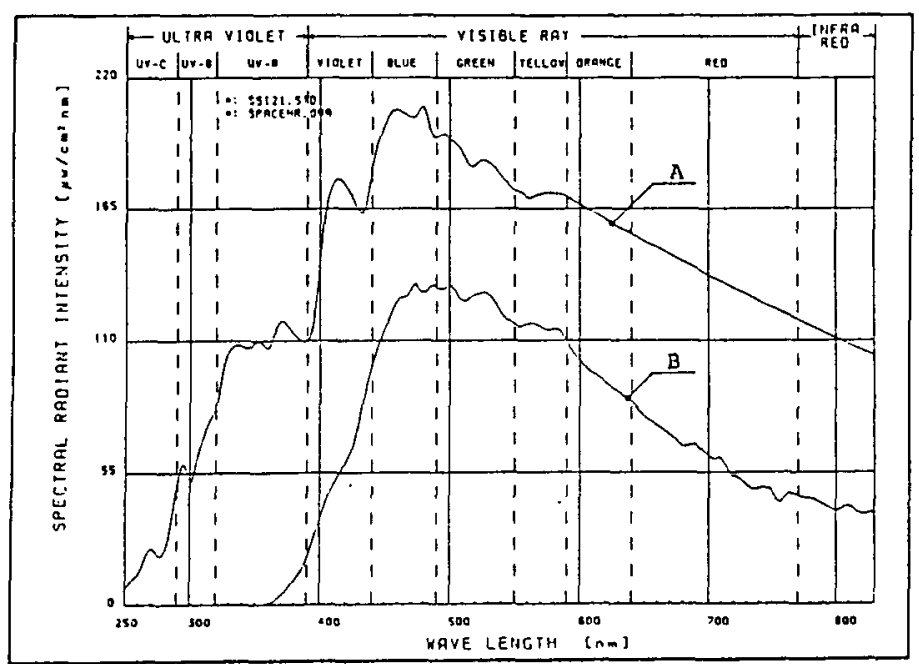

A : Solar spectrom (solar constant) in space near the earth.

$B$ : The same spectrun after passing through a llimawari hight collector of 608 transmissivity.

Fig.3 Graph demonstrating the Himawari Light Collector's visible spectrum transmissivity and its blocking of $U V$ and IR wavelengths in space.

connected to an optical fiber branched off from the main trunk.

\section{Microalgal Bioreactor System}

Within the hexagonal bioreactor tank, the tubular fiber-optic light radiators $/ 3 /$ are arranged vertically in a uniform pattern to provide a high radiative surface per volume of algal suspension (Figures 4 and 5). Light entering the tank through the fiber-optic cables passes into acrylic optical rods (light guides), which form the centers of the light radiators. The cladding of these radiators has a lower refractive index than conventional quartz optical fibers.

Direct immersion of the acrylic rods in the algal suspension results in little light efflux as well as clogging of the light openings with microalgae. Encasing the rods in

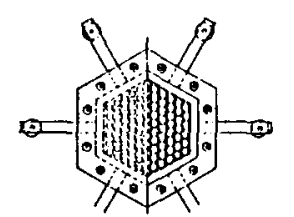
air-filled acrylic tubes solves both problens, and also helps scatter the light. The maximum light path through the suspension from luminant surface to algal cell is $1.5 \mathrm{~mm}$, and most cells are illuminated from all sides. Wedge-shaped cuts passing through the cladding and spaced at one-centimeter intervals allow light to escape evenly along the rod length to illuminate the algal suspension (Figure 5). 
Figure 6 shows a schematic flow diagram of the system used for measurement of carbon dioxide dissolution into the solution from the gas phase. It uses a hollow fiber module made of micro-porous polypropylene membrane, which was supplied by the Mitsubishi Rayon Co. Ltd.. Figure 7 shows the schematic flow diagram of the system used to recover dissolved oxygen from the solution, which uses the same hollow fiber module. The bore of the hollow fiber was kept at reduced pressure so as to increase partial pressure difference of $\mathrm{O}_{2}$ over the micro-porous membrane.

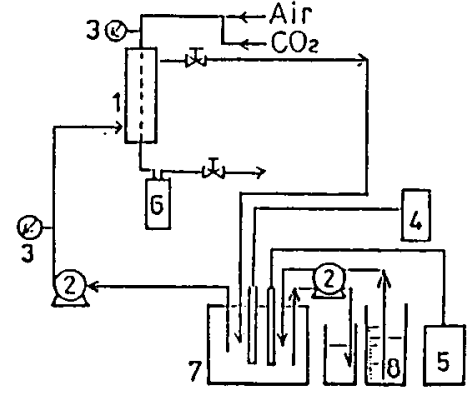

1. Ilollow Fiber Module 2.Pum 3.Pressure Gauge 4. $\mathrm{CO}_{2}$ Desitameter 5.pll Controller 6.Trap 7.Bioreactor B.Naai Solution

Fig.6 Apparatus for measurement of carbon dioxide dissolution using hollow fiber module.

Theoretical methods. Carbon dioxide dissolution. The bioreactor contained one liter of pure water, which was circulated through the module at a fixed flow rate (Figure 6). The mixture of air and $\mathrm{CO}_{2}$ was fed into the bore of the hollow fiber and dissolved into the water flowing outside of the fiber. The concentration of $\mathrm{CO}_{2}$ in the water, $\mathrm{C}_{\mathrm{AL}}$, was measured by $\mathrm{CO}_{2}$ destometer and recorded. Assuming overall mass transfer coefficient, $K_{L}$, constant, $C_{A L}$ at any time may be expressed by the following equation:

$$
\begin{aligned}
& \frac{C_{A}-C_{A L}}{C_{A}-C_{0}}=\exp \left(-K_{L} \cdot a \cdot t\right) \\
& \text { where } C_{A}=H \cdot P_{A}
\end{aligned}
$$

$P_{A}, H$, and a are partial pressure of $\mathrm{CO}_{2}$ in the gas mixture, Henry's constant, and specific membrane area, respectively.

Oxygen recovery. Water dispersed with tiny bubbles of air (instead of oxygen) was fed into the module, where it flowed outside of the hollow fiber. The bubbles attached to the surface of the micro-porous membrane and disappeared gradually; they were sucked through the membrane because the pressure of the bore was kept at about $180 \mathrm{~mm} \mathrm{Hg}$. Water did not permeate through the membrane.

Characteristic. Figure 8 shows the effects of concentration of $\mathrm{CO}_{2}$ on $\mathrm{KL}$ at two levels of water flow rate. Figure 9 shows the effects of water flow rate on $\mathrm{K}_{\mathrm{L}}$. The values of $\mathrm{K}_{\mathrm{L}}$ shown in figure were analyzed by Wilson's method to obtain liquid phase mass transfer coefficients, $K_{L}$, and $k_{G}$. The overall mass transfer coefficient, $K_{L}$, in this case may be expressed as follows:

$$
\begin{aligned}
& \frac{1}{K}=\frac{1}{K_{L}}+\frac{I}{D}+\frac{1}{H \cdot K_{G}} \\
& \frac{1}{K_{L}}=1.28 \cdot 10^{-7} \cdot v^{0.6} \\
& \text { where } D / I=0.248[\mathrm{~m} / \mathrm{s}]
\end{aligned}
$$

Where $I$ and $D$ are membrane thickness and diffusivity, respectively, of $\mathrm{CO}_{2}$ in the gas mixture. $\mathrm{V}$ is flow rate of water in terms of $\mathrm{m}^{3} / \mathrm{s}$.

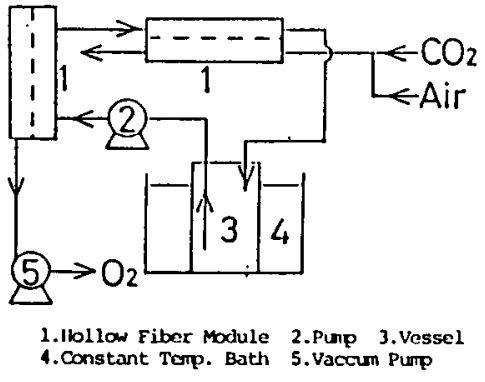

Fig.7 Oxygen recovery system.

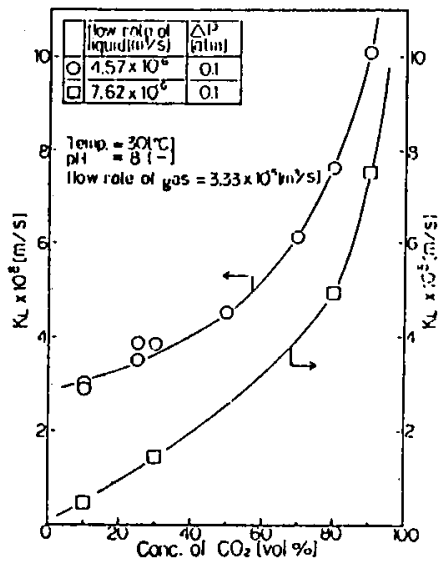

Fig. 8 Over-all mass transfer coefficient $\mathrm{K}_{\mathrm{L}}$ heavily depends on the concentration of carbon dioxide in the gas mixture.

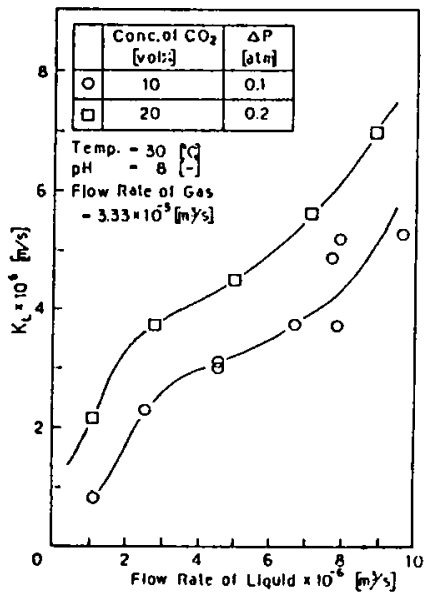

Fig. 9 over-all mass transfer coefficient $\mathrm{K}_{\mathrm{L}}$ increases with flow rate of Iiquid. 
The bioreactor system consists of the light $\infty$ llection and transmission apparatus, the photoautotrophic bioreactor, and the membrane device for gas exchange (Figure 10). Measurement and control devices were employed for experimentation.

\section{Bioreactor Testing without Gas Exchange System}

Apparatus and methods. The light collector, called the "HIMAWARI" $/ 4 /$, is produced commercially by a Tokyo-based engineering firm, La Foret Engineering and Information Service Co., Ltd. . The optical fibers are specially manufactured to be transparent to the visible spectrum (transmissivity of $96 \%$ per ten meters), since those used in the cormunications industry are transparent to the infrared region.

Chlorella was cultivated within the bioreactor in two medium mixtures, one of pH 4.0-4.5 consisting of $(\mathrm{mg} / \mathrm{L}): \mathrm{N}, 63.572 ; \mathrm{P}, 227.608 ; \mathrm{K}$, $287.308 ; \mathrm{Na}, 4.689 ; \mathrm{Mg}, 394.458 ; \mathrm{Fe}, 0.500 ; \mathrm{B}$, $0.500 ; \mathrm{Mn}, 0.500 ; \mathrm{Cu}, 0.200 ; \mathrm{Mb}, 9.784$, and one consisting of Mayers-4NA5. Innocula were cultivated for two or three weeks in aerated and illuminated $\left(58 \mathrm{CO}_{2}\right.$ air at $30 \mathrm{~L} / \mathrm{h}$ and $10,000 \mathrm{~lx}$ ) glass bottles before being suspended in the bioreactor medium.

Results. Figure 11 shows the effect of temperature of chlorella solution upon the growth rate of chlorella. Although such temperatures are commonly much higher, the optimm growth temperature for chlorella occurred at $24-26^{\circ} \mathrm{C}$ for this bioreactor at the gas mixture given earlier, perhaps because of the unique nature of visible spectrum light. Figure 12 shows that the rate of chlorella density change increases with density but levels off due to attenuation of the incoming light. Eventually, the rate of density change is adversely affected by increasing the density and an optimm is reached. To control the density constantly is thus found to be an important operation for minimum energy loss. Figure 13 shows that the rate of chlorella density change changes linearly with respect to the visible light transmission energy. By approximating this linear relationship, higher value data points were plotted.

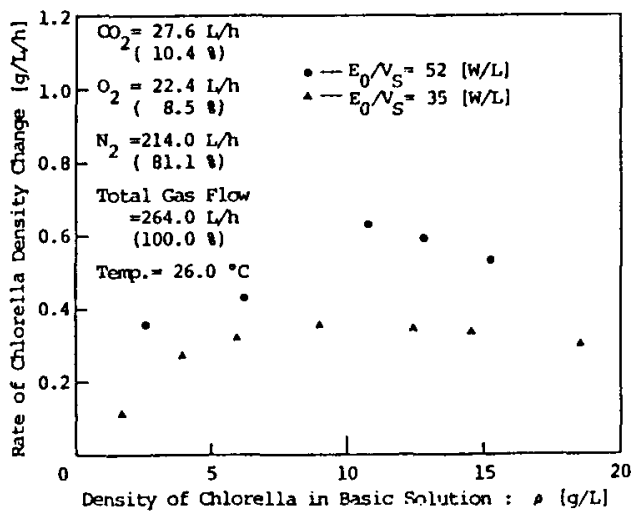

Fig. 12 Relationship between rate of chlorella density change and density of chlorella in basic solution.

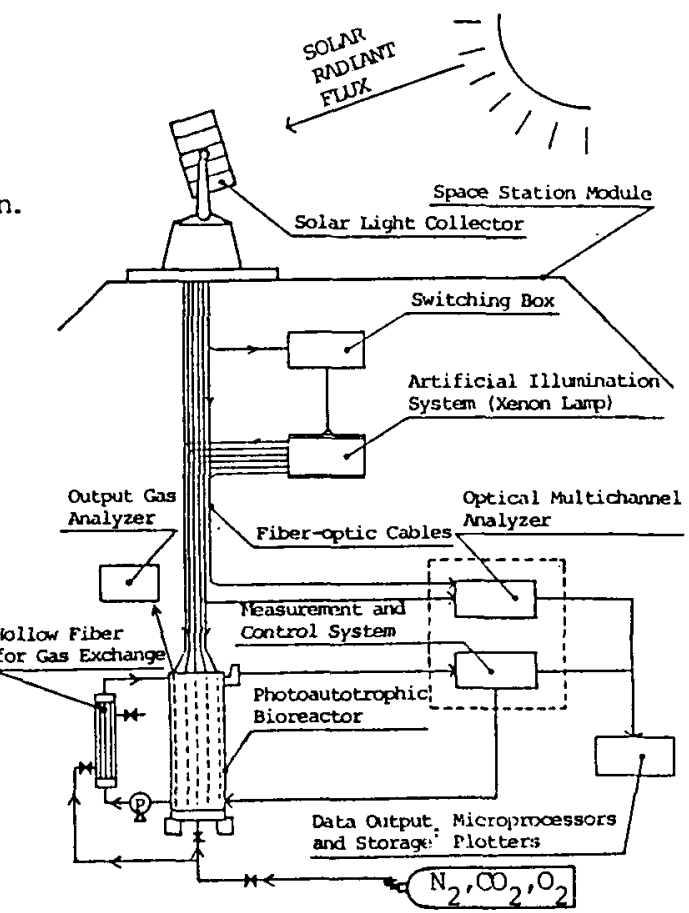

Fig.10 Bioreactor system schematic diagram.

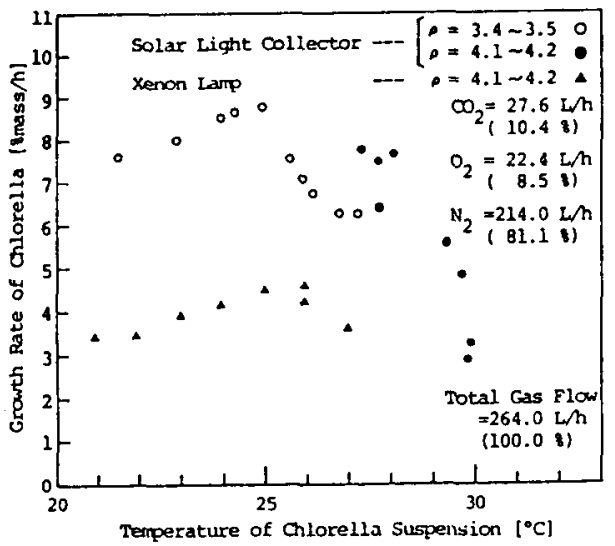

Fig. 11 Effect of temperature of chlorella growth rate.

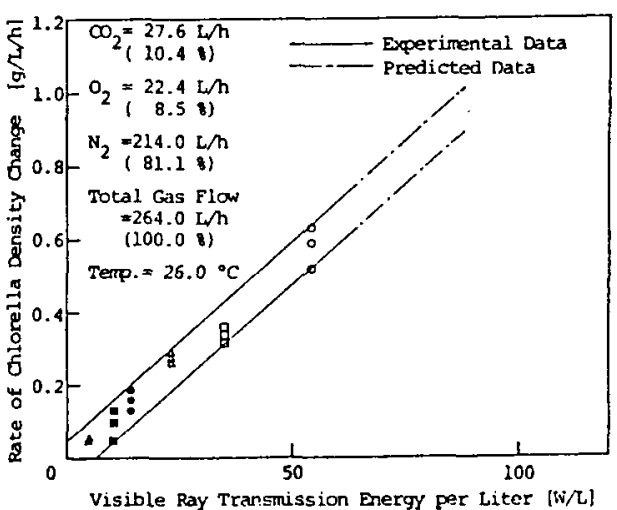

Fig. 13 Relationship between rate of chlorella density change and visible ray transmission energy per liter. 
Apparatus and methods. In this testing membrane for gas exchange, the silicone-rubber hollow fiber module was used because this one did not show loadings and a change with passage of operation time. The value of silicone $k_{L}$ $\left(8.4 * 10^{-6}[\mathrm{~m} / \mathrm{s}]\right)$ is higher than polypropylene one. The membrane unit case is made of glass and can be autoclaved. This membrabe device was designed by La Foret Engineering, and manufactured by Fuji-Systems Co.. Its specifications are shown in Figure 14.

The operation conditions of gas exchange system are shown in Table 1. Input power levels of the Xenon lamp were $9 \mathrm{~W}$, $5 \mathrm{~W}$, and $3 \mathrm{~W}$ in repeated cycles. The incident light intensity in a low earth orbit typically consists of alternating periods of thirty minutes of darkness and sixty minutes of light. Xenon lamps are used as an artificial, controllable source of illumination because of the similarity of their visible spectrum to that of the sun.

Xenon lamps coupled with parabolic mirrors to produce a parallel flux can use the same chromatic aberration filtering and fiber-optic ducting as that of sunlight. Because the lamps are separated from the bioreactor by the fiber-optic cables, waste heat is not a concem.

The chlorella solution recycled through the bioreactor and membrane device for gas exchange. The levels of $D O$ and $\mathrm{DCO}_{2}$ were controlled through the pressure and flow rates of the $\mathrm{O}_{2}$ and $\mathrm{N}_{2}$ supplies. In this test, the level of $\mathrm{O}_{2}$ production could not be analyzed directly. Therefore, the level of $\mathrm{O}_{2}$ production and chlorella production were calculated by the rate of $\mathrm{DCO}_{2}$ change.

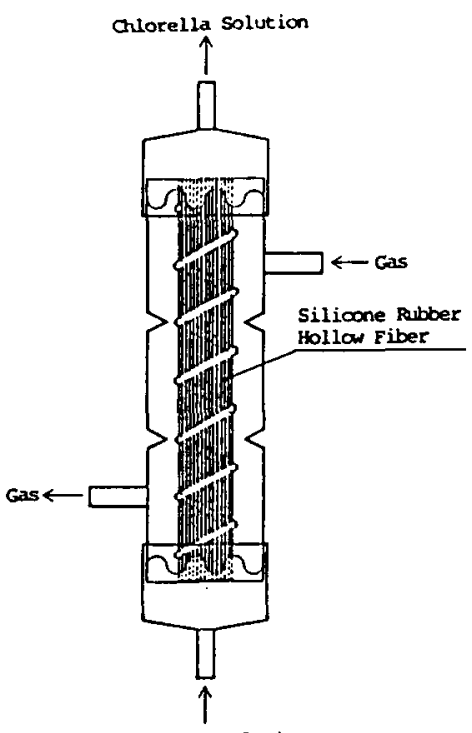

Chlorella solution

\begin{tabular}{|c|c|}
\hline Material & Silicone Rubber \\
\hline Inner Diameter & 0.60 \\
\hline External Diameter [m] & 0.90 \\
\hline Wall Thickness & 0.15 \\
\hline Effective $\quad\left(\mathrm{m}^{2}\right)$ & 0.082 \\
\hline
\end{tabular}

Fig.14 Merbrane device for gas exchange.

Table 1 Comparision between Silicone and Polypropylene.

\begin{tabular}{|c|c|c|c|c|c|c|c|c|c|c|c|}
\hline & \multicolumn{2}{|c|}{ Specification } & \multicolumn{7}{|c|}{ Operating condition } & \multicolumn{2}{|c|}{ Permeability ) } \\
\hline $\begin{array}{l}\text { Cas exchange } \\
\text { membrane }\end{array}$ & $\begin{array}{l}x_{K} \\
\left( \pm 10^{-} \delta_{m / / 3}\right)\end{array}$ & 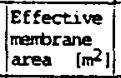 & \begin{tabular}{|r|}
$\begin{array}{r}\text { Volume of } \\
\text { solution } \\
\text { [L }\end{array}$ \\
\end{tabular} & $1-1$ & [atm] & $\begin{array}{l}\text { Fion rate } \\
\text { of } 2 \text { iqquic } \\
k^{*} 100^{-5} \mathrm{~m} / \mathrm{s}\end{array}$ & $\begin{array}{l}\text { low rate } \\
\text { gas } \\
10^{-5}-5_{\mathrm{m} / \mathrm{s}}\end{array}$ & Terp. & 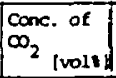 & $\mathrm{O}_{2}$ & $\infty_{2}$ \\
\hline Silicone & 8.4 & 0.082 & 3.1 & $\begin{array}{l}4.5 \\
\sim 6.5\end{array}$ & 20 & 8.33 & 8.33 & 25 & 10 & $\begin{array}{l}1.57 \\
* 1.0^{6}\end{array}$ & $\begin{array}{l}8.04 \\
\star 10^{6}\end{array}$ \\
\hline Polypropylene & $\begin{array}{l}0.9 \\
\sim 6.9\end{array}$ & 0.500 & 1.0 & 8.0 & $\begin{array}{l}0.10 \\
\sim 0.20\end{array}$ & 3.33 & $\begin{array}{l}0.10 \\
\sim 0.90\end{array}$ & 30 & $\begin{array}{l}10 \\
\sim 20\end{array}$ & $\begin{array}{l}2.90 \\
\star 10^{3}\end{array}$ & $\begin{array}{l}9.91 \\
* 10^{3}\end{array}$ \\
\hline
\end{tabular}

1) membrane thickness $25 \mu$ conversion, $25^{\circ} \mathrm{C}, \mathrm{cm}^{3} / \mathrm{m}^{2} \cdot \mathrm{atm} \cdot 24 \mathrm{~h}$

Results. Figure 15 shows Orbit cycle lights alternation's effect on $\mathrm{DCO}_{2}$ and $\mathrm{DO}$ concentration. During the light periods $\mathrm{DO}$ concentration increased while that of $\mathrm{DCO}_{2}$ decreased.

The opposite occurred during the dark periods. The photosynthetic reaction was demonstrated from Figure 15. During each illumination cycle, the $\mathrm{DO}$ and $\mathrm{DCO}_{2}$ concentration pattern was repeated. Figure 16 shows the relationship between visible ray transmission energy and rate of $\mathrm{O}_{2}$ production. The performance of the membrane gas exchanger was constant through the long duration of the experiment.

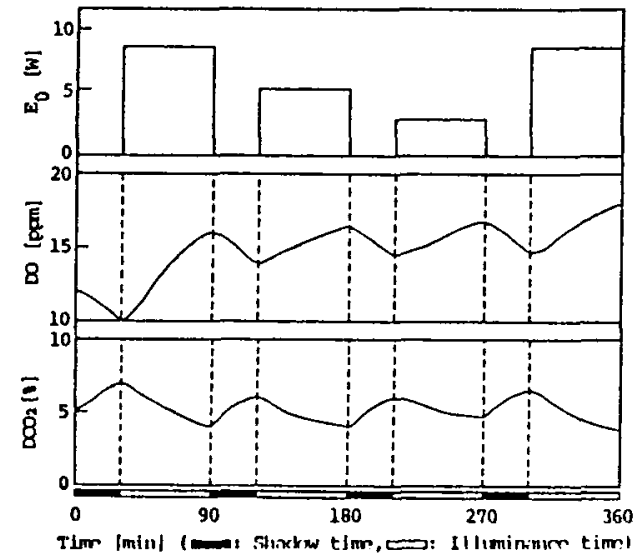

Fig. 15 Orbit cycle altemating light's effect on $\mathrm{DCO}_{2}$ and $\mathrm{DO}$ concentration.

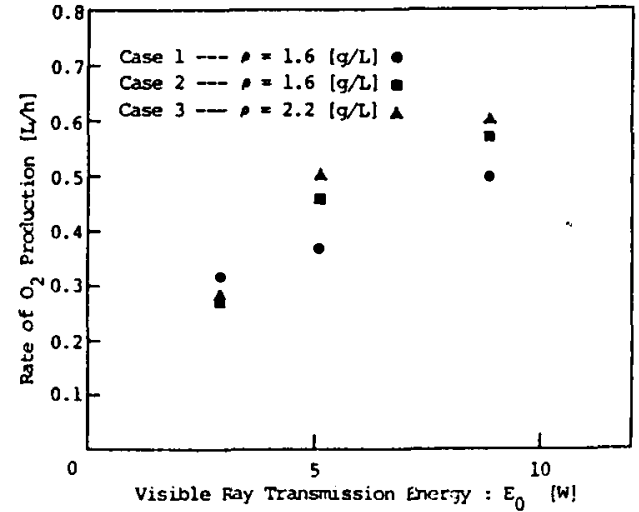

Fig. 16 Relationship between rate of $\mathrm{O}_{2}$ production and visible ray transmission energy. 


\section{CONCLUSIONS}

The bioreactor with sunlight supply system and gas exchange systems presented here has proved feasible in ground tests and shows much promise for space use as a CELSS device. our chief conclusions concerning the specification of total system needed for a life support system for a man in a space station are the following (Table 2).

(1) Sunlight supply system : area of solar ray receiving lens : $6.29-9.37 \mathrm{~m}^{2}$, electrical power consumption : $37-56 \mathrm{~W}$.

(2) Bioreactor system : volume of chlorella solution : $50 \mathrm{~L}$, radiative surface per liter : $0.58 \mathrm{~m}^{2} / \mathrm{L}$, size of bioreactor tank : $0.4 \mathrm{~m} \phi \times 1.0 \mathrm{~m}$.

(3) Gas exchange system : effective membrane area of silicone-rubber hollow module : $1.33 \mathrm{~m}^{2}$ Chlorella photosynthetic efficiency is $7 \%$, which is higher than that one of high plant $10.1-$ 1.08). Microalgal bioreactor system will be best system for a life support system in a space station.

Table 2 Required performance and simulated specification of total system.

\begin{tabular}{|c|c|c|c|c|c|c|c|}
\hline Case & \multicolumn{2}{|c|}{$\bar{I}$} & \multicolumn{2}{|c|}{ II } & \multicolumn{2}{|c|}{ III } & \multirow{3}{*}{ source } \\
\hline Light condition & \begin{tabular}{|c|} 
Illuminance \\
time: \\
60 (minl
\end{tabular} & $\begin{array}{l}\text { Shadow } \\
\text { time: } \\
30 \text { [minl }\end{array}$ & \begin{tabular}{|c|} 
Tlluminanas \\
time: \\
60 [min]
\end{tabular} & $\begin{array}{l}\text { Shadow } \\
\text { time: } \\
30 \text { (min) }\end{array}$ & $\begin{array}{l}\text { Thluminance } \\
\text { time: } \\
60 \text { (min) }\end{array}$ & $\begin{array}{l}\text { Shadow } \\
\text { time: } \\
30 \quad[\text { min } \mid\end{array}$ & \\
\hline Light source & $\begin{array}{c}\text { Solar ray } \\
E_{0}\end{array}$ & $\begin{array}{c}\text { Xenon lanto } \\
E_{0} * 1008\end{array}$ & $\begin{array}{c}\text { Solar ray } \\
E_{0}\end{array}$ & - & $\begin{array}{c}\text { Solar ray } \\
E_{0}\end{array}$ & $\begin{array}{c}\begin{array}{c}\text { Xenon lamp } \\
E_{0}{ }^{*} 108\end{array} \\
\end{array}$ & \\
\hline $\begin{array}{l}\left.\text { Total mass of } \mathrm{O}_{2} \text { produced per } 1,2\right) \\
\text { day in tank } \\
\text { (g/day) }\end{array}$ & \multicolumn{2}{|c|}{$686 * 1.1=754.6$} & \multicolumn{2}{|c|}{$686^{\star} 1.1=754.6$} & \multicolumn{2}{|c|}{$686 * 1.1=754.6$} & Ref.5 \\
\hline $\begin{array}{l}\text { Average mass of } \mathrm{O}_{2} \text { produced per } \\
\text { hour during light time } \\
{[\mathrm{g} / \mathrm{h}]}\end{array}$ & 31.4 & 31.4 & 47.2 & - & 44.9 & 4.49 & \\
\hline $\begin{array}{l}\text { Olorella biomass produced per } \\
\text { hour } \\
\text { holl }\end{array}$ & 29.5 & 29.5 & 44.2 & - & 42.1 & 4.21 & \\
\hline $\begin{array}{r}\text { Rate of chlorella density change } \\
\qquad(\mathrm{g} / \mathrm{L} / \mathrm{h})\end{array}$ & 0.59 & 0.59 & 0.88 & - & 0.84 & 0.08 & \\
\hline Volume of chlorella solution & \multicolumn{2}{|c|}{50} & \multicolumn{2}{|c|}{50} & \multicolumn{2}{|c|}{50} & \\
\hline Radiative surface per liter $\left[\mathrm{m}^{2} / \mathrm{L}\right]$ & \multicolumn{2}{|c|}{0.58} & \multicolumn{2}{|c|}{0.58} & \multicolumn{2}{|c|}{0.58} & Ref.2 \\
\hline $\begin{array}{l}\text { Visible ray transmission energy } \\
\text { per liter needed in tank } \\
\text { per }\end{array}$ & $49^{\text {a) }}$ & $49^{a)}$ & $73^{b)}$ & - & $69^{b l}$ & $6.9^{a 1}$ & Fig. 13 \\
\hline Temperature range of solution $\left.{ }^{\circ} \mathrm{C}\right]$ & \multicolumn{2}{|c|}{$25 \pm 1$} & \multicolumn{2}{|c|}{$25 \pm 1$} & \multicolumn{2}{|c|}{$25 \pm 1$} & Fig.11 \\
\hline $\begin{array}{l}\text { Density range of chlorella in } \\
\text { solution }\end{array}$ & \multicolumn{2}{|c|}{ about $10^{a}$} & \multicolumn{2}{|c|}{ about $15^{b)}$} & \multicolumn{2}{|c|}{ about $15^{\mathrm{b})}$} & Fig. 12 \\
\hline $\begin{array}{l}\text { Chlorella photosynthetic } \\
\text { efficiency: Xe }\end{array}$ & \multicolumn{2}{|c|}{7} & \multicolumn{2}{|c|}{7} & \multicolumn{2}{|c|}{7} & formula (5) \\
\hline $\begin{array}{c}\text { HIMAWARI transmigsion efficiency } \\
: \eta\end{array}$ & 60 & - & 60 & - & 60 & - & Ref.1 \\
\hline $\begin{array}{cc}\text { Area of solar ray reoeiving less } \\
: \mathrm{s}_{\mathrm{L}} & {\left[\mathrm{m}^{2}\right]}\end{array}$ & 6.29 & - & 9.37 & - & 8.85 & - & formula (6) \\
\hline $\begin{array}{c}\text { Visible ray transmission energy } \\
: \mathrm{E}_{0}\end{array}$ & 2450 & 2450 & 3650 & - & 3450 & 345 & formula (6) \\
\hline $\begin{array}{c}\text { Electrical power consumption } 4,5), 5 \\
\mid(w)\end{array}$ & 37 & 24500 & 56 & - & 53 & 3450 & Ref. 6 \\
\hline Gas exchange module & \multicolumn{6}{|c|}{ Silicone-rubber hollow fiber } & Fig. 14 \\
\hline Effective mentbrane area & \multirow{2}{*}{\multicolumn{6}{|c|}{$\frac{\operatorname{Max} .0 .082 \star 50[\mathrm{~L}] / 3.1[\mathrm{I}}{145 \phi \star 450}$}} & Fig. 14 \\
\hline Size of module & & & & & & & \\
\hline
\end{tabular}

\section{a) experimental data b) predicated data}

1) Average mass of $O_{2}$ needed per day for a man in a space station is $686 \mathrm{~g} / 5 /$.

2) The rate of $\mathrm{O}_{2}$ consumption as chlorella respitation (basal metabolism) is 10 of photosynthetic biomass.

3) Definition of the formula

$$
\begin{aligned}
& x_{e}=\frac{\Delta C h \cdot E_{c h}}{E_{0} \cdot 860}[\mathrm{cal} / W) \quad \text { (S) } \quad, E_{0}=A \cdot k \cdot S_{L} \cdot 7 \quad \text { (6) } \\
& \Delta C h: \text { change in total mass of chlorella }[g] \quad E_{c h} \text { : energy per unit bionass chlorella : } 5.6[\mathrm{kcal} / \mathrm{g}]
\end{aligned}
$$

4) The electrical power consumption of HINWWNRI per one scquare meter of lens is $5.93\left(\mathrm{w} / \mathrm{m}^{2}\right) / 6 /$.

5) The rate of kenon lamp electrical power change for visible ray transmission energy is 10 [8].

\section{REFERENCFS}

1. K. Mori, N. Tanatsugu and M. Yamashita, Visible solar-ray supply system for space station, Acta Astronautica, (the Journal of the International Academy of Astronautics), Vo1.13, No.2, p.71 (1985)

2. K. Mori, Photoautotrophic bioreactor using visible solar rays condensed by Fresnel lenses and transmitted through optical fibers. Biotechnology and Bioengineering, No.15, p.331 (1986) John Wiley \& Sons, Inc.

3. K. Mori (inventor), "Photoradiator", Japanese Patent Application No.78,809/82, 78,810/82, 97,459/82, $99,775 / 82$.

4. K. Mori (inventor), "Apparatus for Collecting and Transmitting Solar Energy", U.S. Patent No.4,461,278

5. R.D. Johnson, A closed life-support system for space colonies, 77-ENAs-18 (1978) ASME publication.

6. M. Oleson and R.L. Olson, Conceptual design option study-controlled ecological life support system (CELSS), NASA Contractor Report 177421, Contract NAS2-11806 (June 1986) 